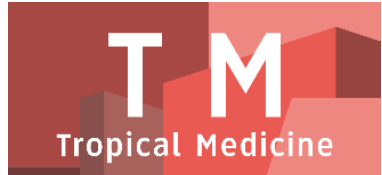

PAPER - OPEN ACCESS

\title{
Inventarisasi Tumbuhan Obat Family Zingiberaceae di Masyarakat Keumala Kabupaten Pidie
}

\author{
Author \\ DOI \\ : Saudah \\ Electronic ISSN \\ : 10.32734/tm.v1i3.265 \\ Print ISSN \\ : 2623-0542 \\ : 2623-0550 \\ Volume 1 Issue 3 - 2018 TALENTA Conference Series: Tropical Medicine (TM)
}

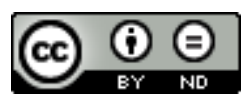

This work is licensed under a Creative Commons Attribution-NoDerivatives 4.0 International License.

Published under licence by TALENTA Publisher, Universitas Sumatera Utara
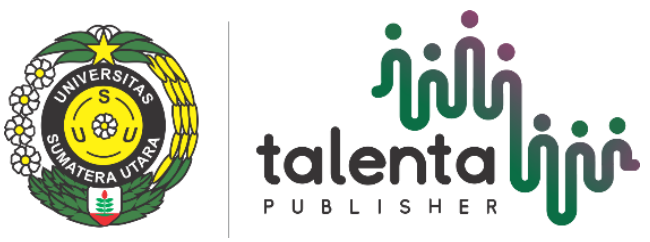


\title{
Inventarisasi Tumbuhan Obat Family Zingiberaceae di Masyarakat Keumala Kabupaten Pidie
}

\author{
Saudah $^{\mathrm{a}^{*}}$, Ernilasari $^{\mathrm{b}}$, Mulia Aria Suzannic ${ }^{\mathrm{c}}$ Irhamni $^{\mathrm{d}}$, Diana $^{\mathrm{e}}$ \\ ${ }^{a b}$ Mahasiswa Magister Pascasarjana MIPA Biologi, Universitas Syiah Kuala, Banda Aceh \\ ${ }^{c}$ Akademi Analis farmasi dan Makanan, Banda Aceh \\ ${ }^{d}$ Fakultas Teknik, Universitas Serambi Mekkah, Banda Aceh \\ ${ }^{e}$ Mahasiswa Magister Pascasarjana MIPA Kimia, Universitas Syiah Kuala, Banda Aceh \\ saudah@serambimekkah.ac.id
}

\begin{abstract}
Abstrak
Penggunaan tumbuhan sebagai obat telah lama digunakan oleh masyarakat Indonesia, terutama masyarakat yang tinggal di pedesaan. Pengetahuan pemanfaatan tumbuhan obat di wariskan secara turun temurun. Seiring dengan perkembangan waktu, kemajuan ilmu pengetahuan dan ilmu teknologi, telah meningkatkan penggunaan tumbuhan obat. Tujuan penelitian ini untuk mengetahui cara masyarakat di Kabupaten Pidiekhususnya di Kecamatan Keumala dalam memanfaatkan tumbuhan obat. Metode yang digunakan adalah metode PRA (Participatory Rural Appraisal), yaitu proses pengkajian yang berorientasi pada keterlibatan dan peran masyarakat secara aktif dalam penelitian yang dikumpulkan melalui wawancara dan observasi. Berdasarkan hasil wawancara diketahui bahwa terdapat 8 spesies tumbuhan obatyang berasal dari family Zingiberaceae yang digunakan sebagai tanaman obat oleh masyarakat Pidie.Spesies tersebut antara lain Temulasi, Temulawak, Halia, Halia Merah, Boh Rangkueh, Boh Cuko, Kunyet Molay, dan Kunyet, yang semuanya berstatus di budidayakan. Bagian yang digunakan adalah Rimpang. Diharapkan penelitian ini berpotensi untuk menemukan jenis tanaman obat baru (bioprospecting) yang bermanfaat bagi farmasi dalam rangka peningkatan kesehatan masyarakat luas.
\end{abstract}

Kata kunci : Tumbuhan obat, Zingiberaceae, Aceh

\begin{abstract}
The use of medicinal plants has long been used by the people of Indonesia, especially people living in rural areas. Knowledge of the use of medicinal plants in hereditary for generations. Along with the development of time, the progress of science and science of technology, has increased the use of medicinal plants. The purpose of this research is to know the way people in Pidie district especially in Keumala Subdistrict in utilizing medicinal plants. The method used is the PRA method (Participatory Rural Appraisal), a process of assessment oriented to the involvement and role of the community actively in the research collected through interviews and observation. Based on the results of the interviews found that there are 8 species of medicinal plants derived from the Zingiberaceae family used as a medicinal plant by the Pidie community. The species include Temulasi, Temulawak, Halia, Halia Merah, Boh Rangkueh, Boh Cuko, Kunyet Molay, and Kunyet, all of whom are in cultivation status. The part used is Rhizome. It is expected that this research has the potential to find new types of medicinal plants (bioprospecting) that are beneficial to pharmaceutical in order to improve public health.
\end{abstract}

Keywords: Medicinal plants, Zingiberaceae, Aceh

\section{Pendahuluan}

Indonesia mempunyai keanekaragaman hayati (biodiversitas) tertinggi kedua setelah Brazil untuk flora dan fauna darat dan bahkan tertinggi jika digabungkan dengan biodiversitas laut. Kekayaan keanekaragaman (biodiversitas) dapat dimanfaatkan dan dikelola dengan optimal sehingga memberikan manfaat, khususnya bagi negara dan dunia secara umum [1]. Biodiversitas adalah keseluruhan gen, spesies dan ekosistem suatu kawasan (totality of ganes, spesies and ecosystems in a region)[2]. Keanekaragaman hayati sangat penting bagi umat manusia karena ketersediaan bahan baku untuk makanan, obat-obatan dan industri.

Tumbuhan obat adalah tumbuhan yang salah satu atau seluruh bagian pada tumbuhan mengandung zat aktif yang berkhasiat bagi kesehatan [3]. Bagian tumbuhan yang dimaksud adalah daun, akar, batang, kulit, umbi, biji dan getah (resin) yang mempunyai khasiat obat dan digunakan sebagai bahan baku dalam pembuatan obat modern atau tradisional [4]. Beberapa kelebihan tumbuhan obat tradisional dibandingkan dengan obat modern yaitu, tidak ada efek samping jika digunakan dengan 
benar, efektif untuk menyembuhkan penyakit yang sulit disembuhkan dengan obat kimia, harga yang terjangkau dan tidakdiperlukan tenaga medis dalam penggunaanya [5]. Pengetahuan tentang pemanfaatan tumbuhan obat sangat penting dan diharapkan dapat mendorong adanya upaya pelestarian untuk jenis-jenis tumbuhan tersebut [6].

Penelitian tentang pengetahuan dan pemanfaatan tumbuhan obat oleh masyarakat lokal telah banyak dilakukan di Indonesia, diantaranya pemanfaatan suku zingiberaceae sebagai obat tradisional oleh masyarakat di Kotamadya Banjarbaru. Dari hasil penelitian tersebut diketahui jenis-jenis tanaman yang dimanfaatkan sebagai obat yaitu : Alpinia galanga, Curcuma longa L atau C. domestica Val., Curcuma xanthorrhiza Roxb., Curcuma aeruginosa, Kaempferia galanga L, Kaempferia. pandurata Roxb., Zingiber officinale Rosc. Etnis yang menggunakan jenis-jenis dari suku Zingiberaceae diantaranya adalah etnik Banjar (61 \%), etnik Jawa (23\%) dan etnis lain $15 \%$ (gabungan dari etnik Madura, Batak, Dayak, Bugis, Sunda dan sebagian kecil Cina) [7].

Selanjutnya, etnobotani medis masyarakat kemukuman Pulo Breueh Selatan ditemukan 67 spesies tumbuhan obat. Bagian tumbuhan yang digunakan sebagai obat adalah, daun, buah, getah, batang, kulit, rimpang, dan umbi. Jenis penyakit yang diobati dengan menggunakan tumbuhan obat beragam yaitu sebanyak 5 jenis penyakit [8]. Masyarakat memanfaatkan tanaman obat dalam kehidupannya untuk mengobati berbagai penyakit. Tumbuhan berkhasiat obat ditemukan pada pekarangan rumah, budidaya atau secara liar. Setiap masyarakat memiliki pengetahuan tentang cara meramu, waktu pengambilan serta cara penggunaan dlam pengobatan tradisioanal. Potensi tumbuhan sebgai obat tradisional terdapat pada berbagai daerah dan di setiap daerah memiliki sistem pemanfaatan tumbuhan obat yang bersifat khas dan berbeda dengan daerah lain. Hal ini dilihat dari jenis tumbuhan yang digunakan, bagian tumbuhan, dan cara penggunaan tumbuhan sebagai obat tradisional.

Kurangnya literatur tentang inventarisasi tanaman obat di Provinsi Aceh khususnya Aceh Pidie telah mendorong minat penulis untuk meneliti, mengidentifikasi dan menginventarisasi lebih lanjut jenis tanaman obat tradisional dari family Zingiberaceae yang sering digunakan dikalangan masyarakat. Survey ini dapat digunakan sebagai dasar untuk menambah literatur etnobotani Aceh khususnya dan Indonesia pada umumnya.

\section{Metode}

Penelitian ini dilaksanakan di Kecamatan Keumala Kabupaten Pidie terdiri dari desa Mesjid Nicah, Pulo Seupeng dan Desa Sago. Metode yang digunakan dalam penelitian ini adalah metode Participatory Rural Appraisal (PRA), yaitu berorientasi pada keterlibatan dan peran serta masyarakat secara aktif dalam penelitian[9]. Keterlibatan masyarakat diperoleh melalui wawancara kepada beberapa sumber yang mengetahui pemakaian tumbuhan sebagai obat tradisional. Wawancara ditujukan kepada pengobat (tabib) dan masyarakat pengguna tumbuhan obat yang mencakup, nama lokal, bagian yang digunakan, manfaat serta status tumbuh. Data yang diperoleh dianalisis secara deskriptif dan ditabulasi dalam tabel.

\section{Hasil dan Pembahasan}

Kecamatan Keumala merupakan salah satu kecamatan yang terkenal dengan lumbung padi di Kabupaten Pidie. Kecamatan Keumala memiliki luas 5.249,28 ha dan letak geografis $04,30^{\circ}-04,60^{\circ}$ LU ; 95,75 $-96,20^{\circ}$ BT. Adapun batas kecamatan Keumala adalah sebelah utara berbatasan dengan kecamatan Sakti, Kecamatan Mila dan Kecamatan Padang Tiji, sebelah Timur berbatasan dengan Kecamatan Titeu, sebelah Selatan berbatasan dengan Kecamatan Tangse dan sebelah Barat berbatasan dengan pengunungan Jantho Aceh Besar. Kecamatan Keumala memiliki 18 desa yang dibagi kedalam dua mukim [10].

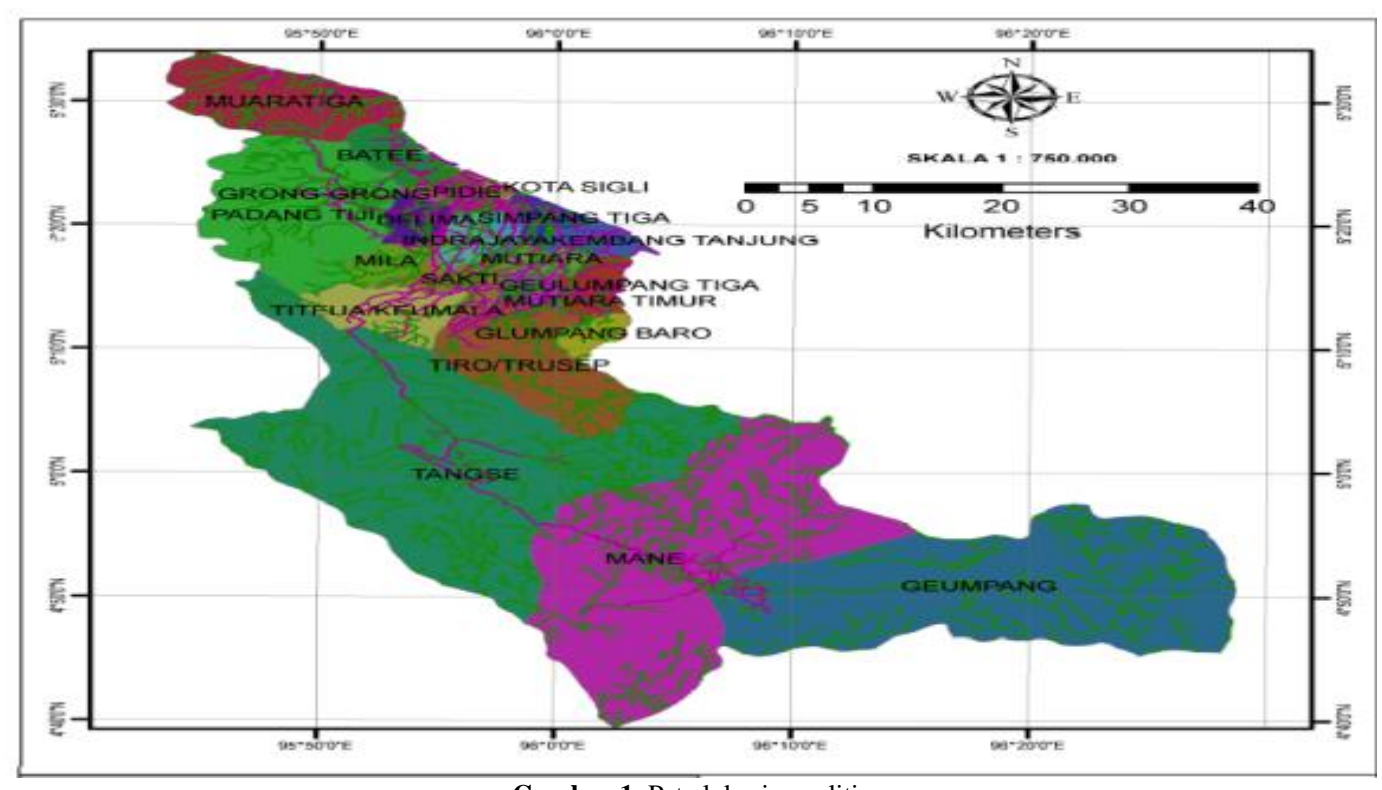

Gambar 1. Peta lokasi penelitian 
Jenis yang dimaksud adalah untuk menggambarkan jumlah seluruh jenis yang diketahui dari hasil wawancara keseluruh responden, baik itu pengguna maupun pengobat. Berdasarkan hasil wawancara diketahui bahwa terdapat 8 spesies dari family Zingiberaceae yang digunakan oleh masyarakat Keumala Pidie (Table 1).

Tabel 1. Jenis tumbuhan yang digunakan oleh masyarakat kabupaten Pidie

\begin{tabular}{|c|c|c|c|c|c|}
\hline No & $\begin{array}{c}\text { Nama ilmiah } \\
\text { / Nama Lokal }\end{array}$ & Famili & Bagian digunakan & Manfaat dan cara pemanfaatannya & Status \\
\hline 1 & $\begin{array}{l}\text { Curcuma paliida Lour } \\
\text { Temulusi }\end{array}$ & Zingiberaceae & Rimpang & $\begin{array}{l}\text { Obat sakit kepala, dan perawatan pasca } \\
\text { melahirkan, } \\
\text { Digiling halus, diminum }\end{array}$ & Budidaya \\
\hline 2 & $\begin{array}{l}\text { Curcuma zanthorrhiza } \\
\text { Temulawak }\end{array}$ & Zingiberaceae & Rimpang & $\begin{array}{l}\text { Penambah nafsu makan, obat sakit kepala, } \\
\text { perawatan pasca melahirkan. } \\
\text { Digiling halus, diminum }\end{array}$ & Budidaya \\
\hline 3 & $\begin{array}{l}\text { Zingiber officinale } \\
\text { Halia merah }\end{array}$ & Zingiberaceae & Rimpang & $\begin{array}{l}\text { Obat patah tulang, masuk angin Digiling } \\
\text { halus di balur. } \\
\text { Di rebus dan di minum }\end{array}$ & Budidaya \\
\hline 4 & $\begin{array}{l}\text { Zingiber officinale } \\
\text { Halia }\end{array}$ & Zingiberaceae & Rimpang & $\begin{array}{l}\text { Masuk angin, badan kurang sehat, gejala } \\
\text { demam, campuran ramuan pasca } \\
\text { melahirkan } \\
\text { Di rebus }\end{array}$ & Budidaya \\
\hline 5 & $\begin{array}{l}\text { Alpina galangal } \\
\text { Boh rangkueh }\end{array}$ & Zingiberaceae & Rimpang & Panu, digosok & Budidaya \\
\hline 6 & $\begin{array}{l}\text { Kaempferia galangal } \\
\text { Boh cuko }\end{array}$ & Zingiberaceae & Rimpang & $\begin{array}{l}\text { Obat batuk, diare, menghilangkan darah } \\
\text { kotor pasca melahirkan } \\
\text { Tumbuk dan di minum }\end{array}$ & Budidaya \\
\hline 7 & $\begin{array}{l}\text { Curcuma longa } \\
\text { Kunyet }\end{array}$ & Zingiberaceae & Rimpang & $\begin{array}{l}\text { Magh, asam lambung, luka, pasca } \\
\text { melahirkan, flu pada anak } \\
\text { Di giling halus di minum } \\
\text { Di tumbuk dan di oles, di gosok pada anak }\end{array}$ & Budidaya \\
\hline 8 & $\begin{array}{l}\text { Zingiber cassumunar Robx } \\
\text { Kunyet Muley }\end{array}$ & Zingiberaceae & Rimpang & $\begin{array}{l}\text { Campuran obat pasca melahirkan. } \\
\text { Ditumbuk halus, diminum. }\end{array}$ & Budidaya \\
\hline
\end{tabular}

Pada tabel 1, didapat 8 spesies tumbuhan obat dari family Zingiberaceae yang digunakan oleh masyarakat Keumala. Spesies tersebut antara lain Curcuma paliida Lour, Curcuma zanthorrhiza, Zingiber officinalspp, Alpina galanga Kaempferia galanga, Curcuma longa, dan Zingiber cassumunar Robx. Spesies tersebut digunakan secara tunggal maupun campuran. Kunyit molay (Zingiber cassumunar Robx) dicampur dengan kunyit (Curcuma longa) dan jahe (Zingiber officinale) digunakan sebagai ramuan pasca melahirkan dengan cara di giling halus dan di tumbuk.Temulawak (Curcuma zanthorrhiza) dijadikan sebagai ramuan penambah nafsu makan dengan cara ditumbuk dan diperas untuk kemudian diminum airnya. Lengkuas (Alpina galanga) digunakan secara tunggal untuk mengobati panu, dengan cara digosokkan pada kulit yang terinfeksi jamur. Menurut [11], lengkuas mengandung minyak atsiri yang berkhasiat sebagai antijamur. Adapun penyakit lainnya yang diobati dengan menggunakan tumbuhan dari family Zingiberaceae adalah masuk angin, mual, sakit kepala, tukak lambung, patah tulang, luka ringan dan beberapa penyakit kulit lainnya. Selain sebagai obat, tumbuhan dari family Zingiberaceae juga digunakan sebagai bumbu masak.

\section{Kesimpulan}

Berdasarkan penelitian didapat 8 spesies tumbuhan obat yang berasal dari family Zingiberaceae. Famili tersebut merupakan famili yang di manfaatkan oleh masyarakat Kecamatan Keumala dalam pengobatan disamping bahan dalam pemenuhan kebutuhan sehari-hari. Proses pengguanaanya dalam bentuk tunggal dan ramuan.Tumbuhan obat ini yang banyak digunakan oleh masyarakat Keumala Kabupaten Pidie, seperti untuk bumbu masak, juga digunakan dalam perawatan pasca melahirkan, patah tulang, masuk angin, mengobati luka dan beberapa penyakit kulit lainnya.

\section{Ucapan Terima Kasih}

Ucapan terima kasih kepada Kemenristek Dikti atas biaya Hibah PDP, LPPM dan Universitas Serambi Mekkah Banda Aceh.

\section{Daftar Pustaka}

[1] Widjaja, E. A., Y. Rahayuningsih., J. S. Rahajoe., R. Ubaidillah., I. Maryanto., E. Baroto dan G. Semiadi. 2014. Kekinian Keanekaragaman Hayati Indonesia. LIPI Pres, Kementerian Lingkungan Hidup dan Bappenas.

[2] Sutarno dan A. D., Setyawan. 2015. Biodiversitas Indonesia : Penurunan dan Upaya dan Pengelolaan Untuk Menjamin Kemandirian Bangsa. Proseding seminar nasional masyarakat biodiversitas, Vol. 1 (1):1-13.

[3] Sada, J.T. dan R. H. R. Tanjung. 2010. Keragaman Tumbuhan Obat Tradisional di Kampung Nansfori Distrik Supiori Utara , Kabupaten Supiori - Papua. Jurnal Biologi Papua. 2: 39-46

[4] Ariyati, E., S. Marlina dan Ruqiah. 2016. Pewarisan Pengetahuan Tanaman Obat Di Desa Garu Kabupaten Landak. Seminar Nasional Pendidikan dan 
Saintek, 774-778.

[5] Karyasari. 2002. Materi Pelatihan Profesional Tanaman Obat. Kelas Profesional. Penyakit dan Pengobatannya. Karyasari Bogor.

[6] Rosiana, A. 2013. Kajian Etnobotani Masyarakat Sekitar Kawasan Cagar Alam Imogiri Bantul Yogyakarta. [Skripsi]. Fakultas Sains dan Teknologi. Universitas Islam Negeri Sunan Kalijaga Yogyakarta.

[7] Kuntorini, E.K. 2005. Botani Ekonomi Suku Zingiberaceae Sebagai Oabt Tradisional Oleh Masyarkat Di Kotamdya Banjarbaru. Bioscientiae. Vol.2 (1):25-36.

[8] Wardiah., Hasanuddin dan Mutmainnah. 2015. Etnobotani Medis Masyarakat Kemukiman Pulo Breuehselatan Kecamatan Pulo Aceh Kabupaten Aceh Besar. Jurnal Edubio Tropika. Vol.3(1):1-50

[9] Nasution, J. 2009. Oukup, Ramuan Tradisional Suku Karo Untuk Kesehatan Pasca Melahirkan : Suatu Analisa Bioprospeksi Tumbuh-tumbuhan Tropika Indonesia. Tesis. Institut Pertanian Bogor.

[10] Badan Pusat Statistik. 2016. Kabupaten Pidie dalam Angka 2016. Kabupaten Pidie: Badan Pusat Statistik.

[11] Rema Rahmalia et al. 2010. Aktivitas Antijamur Krim Minyak Atsiri Rimpang Lengkuas (Alpinia galanga L.) terhadap Candida albicans. Jurnal Pharmacy. Vol 7 (2). 